\title{
Design of a System Dynamics Model (SDM) to Evaluate the Supply Chain of Biological Products
}

\author{
Salameh Seraji*, Hasan Mehrmanesh*, Ahmad R. Kasraee* \\ * Department of Industrial Management, Central Tehran Branch, Islamic Azad University, Tehran, Iran \\ (s.seraji@gmail.com,hsn.mehrmanesh@gmail.com, kasraei49@yahoo.com) \\ Hasan Mehrmanesh, Tel:+98 9123605730 \\ hsn.mehrmanesh@gmail.com
}

Received: 17.11.2020 Accepted: 28.05.2021

\begin{abstract}
Today, organizational agility in a competitive business environment has become the primary principle of success. In the supply-chain management of any organization, its suppliers play an important role in achieving this significant goal. Therefore, the importance of evaluation in selecting and cooperating with suppliers plays a noteworthy role in increasing the chances of success. Meanwhile, identifying the supplier's evaluation indicators in a dynamic and uncertain environment has become a major challenge for managers. This article tries to provide an accurate and reliable solution to this important challenge based on the design of a System Dynamics Model (SDM). Thereby, the main purpose of this paper is to provide a model for evaluating suppliers in the biological supply chain. Then, the reliability and accuracy of the proposed model, are evaluated with several statistical tests. Finally, the performance of this model is shown in the supply chain of a vaccine and serum Institute. The results obtained, both in the tests and in the case study, all indicate the model's ability, reliability, and high accuracy in evaluating suppliers.
\end{abstract}

Keywords- System Dynamics Model; Biological Supply Chain; Supplier Evaluation System, Cause and Effect Diagram, Stock-Flow Diagram.

\section{Introduction}

Rapid and unavoidable changes in today's world due to the phenomenon of globalization and the headlong advancement of science in economic, political, and industrial dimensions -especially in the last two decades- have led to dramatic technological developments within the field of information and communication. The speed and acceleration of these changes in different dimensions have led managers to improve the internal processes of organizations in order to maintain the survival power in a market that is becoming more competitive every day [1]. In today's global competition, it is necessary to make a variety of products available to customers according to their requirements. Customer expectations of high quality and fast service have increased the pressure on companies that did not exist before. Therefore, companies cannot independently meet all customer needs and expectations [2]. Therefore, in addition to overseeing their internal affairs, organizations need to focus on managing and evaluating matters outside the organization. The main goal of this issue is to achieve competitive advantages to gain more market shares [3].

With the increasing complexity of information, the strategic focus of companies is constantly changing. Therefore, the competitive environment in this market is inevitable. Many active companies acknowledge that today's competition is, in fact, competitive in the supply chain and that the focus on supply chain management will be the most important source of competitive advantage [4]. Therefore, the fundamental role of suppliers in improving the performance of the supply chain has made it important to identify the criteria for ranking and selecting suppliers $[5,6]$.

Today's past production management models, which have been less integrated into their processes, have lost their effectiveness, and integrated supply chain models as a harmonic approach to the proper management of materials, goods, information, and finance have the ability to respond to conditions[7]. As organizations become more dependent on suppliers, the direct and indirect consequences of wrong decision-making become more detrimental. The globalization of trade and the growing expansion of the Internet has 
increased the variety of supplier selection techniques. Acquiring customer satisfaction, meeting customer needs, and priorities requires a prompt and appropriate selection of suppliers [8]. New organizational structures have led to more people being involved in decision-making to select suppliers, and therefore, the position and value of decision-making have increased [9]. The complexity and importance of decisionmaking in selecting suppliers clearly illustrates the need for a clear and transparent approach. Improper choice of suppliers can disrupt the financial and technical position of a supply chain [10]. Due to the increasing interest of companies in strategic cooperation with key suppliers during the productdevelopment process, the team responsible for selecting suppliers must use tools to be able to classify suppliers based on their capabilities and performance. Many successful companies believe that selecting a supplier is one of the most important activities of organizations [11]. Therefore, choosing the right supplier in chain management is a challenging issue. Meanwhile, in the supply chain of biological products, in order to provide timely and quality materials, this issue is of special importance in the field of planning, control, and evaluation [12]. Given the importance of this issue and the fact that in recent years, the industry of production of biological products has undergone many changes, the most important of which is the globalization of markets, changes in technology, changes in customer needs and reduced product life cycle, besides, the key role of suppliers in improving this chain led to the issue of selecting suppliers by identifying the most important criteria in dynamic environmental conditions in this study.

Considering that strategic cooperation with suppliers is necessary to provide high-quality materials and reduces the delivery time of the projects in the Razi Vaccine and Serum Research Institute (RVSRI), it seems essential. Therefore, one of the goals of this Institute in a competitive environment is to provide quality requirements promptly and at a reasonable cost according to other performance indicators. Given this, the selection of suppliers has had a significant impact on achieving these goals, and this process is critical to the success of RVSRI. It should be noted that the greater dependence of RVSRI on its suppliers could have irreparable consequences for this institution. The high cost and sensitivity of the materials and equipment required, as well as the need for global standards, on the one hand, and the importance of their timely delivery on the other, make the process of selecting suppliers more sensitive and require more precision. Creating a dynamic decision-making system under the characteristics and feedback of suppliers based on the

Indicators of the Razi Institute is one of the main goals of this organization. Despite much research into the evaluation and selection of suppliers, the Institute continues to suffer from a lack of system dynamics (SDs) in various fields. Especially in Razi Institute, considering the huge volume of purchases and their preparations and sensitivity, as well as the uncertainty in parameters and variables, the evaluation and selection of suppliers of the Institute based on the SDM are very important and vital. Therefore, in this study, the simulation of a dynamic system has been used for modeling to evaluate suppliers in the Razi Institute. The purpose of this paper is to achieve a general strategy in evaluating and selecting providers of the Razi Institute and to provide a model in dynamic conditions.

The results of the dynamic system model with integration of qualitative and quantitative metrics are designed to evaluate the interaction and relevance of factors that some of them may conflict even with each other. The model structure is designed to be considered among the suppliers, so that if any of the suppliers face the risk, they may act to cause changes and improve their performance. Considering the four suppliers and parameters associated with them, which consists of 16 criteria, compared to suppliers in different time periods, the results from the dynamic system model results in ranking and supplier selection. Finally, after simulation, the validity of the model was investigated by several tests including boundary sufficed test, structure evaluation test, boundary conditions test and integrity test, which confirmed the results obtained from the dynamic system model.

\section{Methodology}

The methodology of this research, from the goal perspective, is in the category of applied research, in terms of how data is collected, is in the category of descriptive (nonexperimental) research and finally, in terms of implementation, falls into the category of survey research. In this paper, an attempt is made to provide a model for evaluating the suppliers of a health supply chain in the biological industry using SDs. The main data of this article have been collected through direct interview and questionnaire.

\subsection{Method of Data Analysis}

In this paper, using the SDs analysis technique, the initial behavior of the effective variables in the evaluation of the providers of the Razi Institute has been performed. Then, causal relationships between the main and secondary factors based on the two techniques of cause and effect diagram and Stock-Flow Diagram have been determined in the SDs approach. The reliability and validity of the proposed model are examined using simulation in VENSIM software. Finally, different scenarios are defined for Razi Institute and by implementing the mentioned model in each scenario, the effects of different decisions on the cost and income of the 
Razi Institute in a certain period of time are determined, and the best scenario is selected.

\section{System Dynamics Modeling (SDs)}

Modeling is a process of feedback, and models are created by performing a series of constant repetitive processes, sequential questions, testing, and optimization. The modeling process is not a very clear process, and it is not possible to prescribe clear steps for all dynamic processes in the same way. In the modeling process, each model maker has different approaches; However, all successful models follow a regular process that includes the following activities:

1. Creating a framework for the problem (System boundary)

2. Create a dynamic hypothesis about the causes of the problem

3. Formulate a simulation model to test a dynamic hypothesis

4. Test the model

5. Design and evaluate policies to improve [13].

Figure 1 shows the modeling process in more detail. The main art of modeling with the SDs is to discover and introduce feedback processes, which, together with the StockFlow diagram, determine the time delays and dynamics of a system, and it helps identify system structural defects.

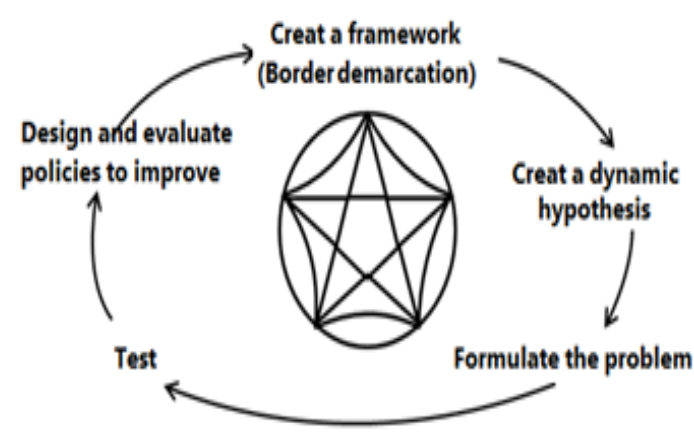

Fig. 1. The main steps of the modeling process

\subsection{System Boundary}

Each system has a boundary that separates it from its surroundings and at the same time connects it to the environment. It can be said that the boundaries of the system are points beyond which the specific features of the system are no longer recognizable. Perhaps if the boundaries of the system are broader, the facts will be much clearer and better understood; However, it should be noted that sometimes expanding the boundaries of the system creates complexities that make it difficult to solve the problem. The model boundary is not predetermined and is determined by the researcher[14].

Table 1. System boundary

\begin{tabular}{|l|l|l|}
\hline Level & Indicator & $\begin{array}{l}\text { Variable } \\
\text { type }\end{array}$ \\
\hline Product & Price & Exogenous \\
\hline & Quality & Endogenous \\
\hline Service & $\begin{array}{l}\text { Variety of production line } \\
\text { delivery }\end{array}$ & Exogenous \\
\hline & Supplier obligations & Endogenous \\
\hline Risk & $\begin{array}{l}\text { Registered business } \\
\text { experiences }\end{array}$ & Exogenous \\
\hline Trade restrictions & Exogenous \\
\hline $\begin{array}{l}\text { Supplier } \\
\text { background }\end{array}$ & $\begin{array}{l}\text { Perception and acceptance of } \\
\text { risk }\end{array}$ & Exogenous \\
\hline Cost & Ability to reduce costs & Endogenous \\
\hline
\end{tabular}

In this study, different indicators such as product type, supplier services, etc. have been considered to evaluate suppliers. Hence the system boundary is given here in the form of $\mathrm{T}$ able 1 . In a way, this boundary of the system represents the scope of the model by identifying and categorizing endogenous and exogenous variables at each level An exogenous variable is a variable whose value is determined outside the model, and a change originating within the model boundary means a change in an exogenous variable. In contrast, an endogenous variable is a variable whose value is determined by the model itself. An endogenous change means a change in an endogenous variable in response to an exogenous change that is imposed upon the model.

As shown in the table, here the system boundary is defined in five levels of product, service, risk, supplier background, and cost, considering the factors such as price, quality, supplier obligations, etc. and other factors are ignored. It should be noted that at each of the levels, several factors were examined, and finally by using the questionnaire and the experts opinion of the mentioned indices.

After identifying the purpose and boundaries of the system, the factors affecting the key variables of the problem must be identified. What variables are effective in evaluating suppliers? In what position and rankings does each supplier have compared to its competitors? What is the status of each supplier in the short and long term? Evaluating suppliers is one of the challenges facing any organization. The 
dependence of this problem with the identification of activities, products, and information requires that the factors involved to be examined. Especially when the researcher needs to be aware of how these factors will affect the longterm or short-term evaluation process to make decisions or make changes.

\subsection{Modeling}

Feedback is the process by which a variable in a series of cause-and-effect relationships, interacts with other variables. There are two types of causal relationships in this regard: [13]

- $\quad$ Positive cause and effect relationship (+): Changing the cause in one direction effect on another variable to change in the same direction (Figure 2a).

- $\quad$ Negative cause-and-effect relationship (-): Changing the cause in one direction effect on another variable to change in the opposite direction (Figure 2b).

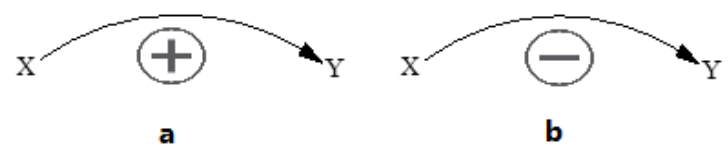

Fig. 2. Positive and negative causal relationship

In this regard, the connections between the components of the system are not linear and are in the form of cause and effect loops. There are two types of loops: Positive (reinforcing) and negative (balancing) loops; A small change in one of the variables within the loop must be traced to determine whether the loop is negative or positive. If the feedback exacerbates the initial change, the loop is positive, and if it is the opposite, the loop is negative. The symbols used for positive and negative loops are as follows (Figure 3):

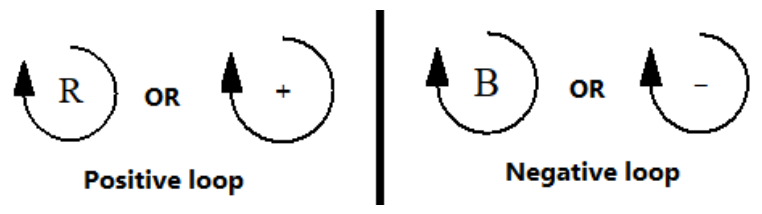

Fig. 3. Feedback loops

\subsection{Cause and Effect Diagrams}

The SDs use a variety of graphical tools to understand the structure of a system, such as cause-and-effect and Stock-
Flow diagrams. A cause-and-effect diagram is an important tool for showing the feedback structure of systems [13]. The most important applications of this diagram are the following:

- Quick access to hypotheses about the causes of dynamics

- Inference and understanding of the mental models of individuals or groups

- Investigating the relationship between important and influential feedback on model performance

Drawing loops and conceptual connection between variables is one of the most important steps in building SDMs. First of all, it should be noted that the performance of each supplier and the ability of each to meet the demands of the organization are determined and evaluated by different factors. Furthermore, the interaction between these indicators can reduce or increase each of them. On the other hand, it is obvious that each of the suppliers does not act individually and is competing with each other and trying to increase its success in meeting the expectations of the organizations. By considering the indicators related to each of the suppliers, the organization tries to select the best supplier according to the goals within the organization and according to it, it tries to formulate its strategies. For example, if two suppliers are evaluated by the experts of the organization and their performance is ranked and scored by different indicators, it is obvious that the demand for purchases from suppliers with higher scores will increase. This will create competition for suppliers who offer the same or similar products. So the two companies are competing to gain more market share. Therefore, if the performance of the supplier number one increases, the demand will increase and it will stimulate the competition of supplier number two. As competition increases, supplier No. 2 will seek to improve its performance. With the increase in the level of performance of supplier number two, the demand for it will increase and the competition of supplier number one will increase. As competition increases, the level of performance of supplier number one increases again. The reinforcing loop of the model with four suppliers is shown in Figure 4. 


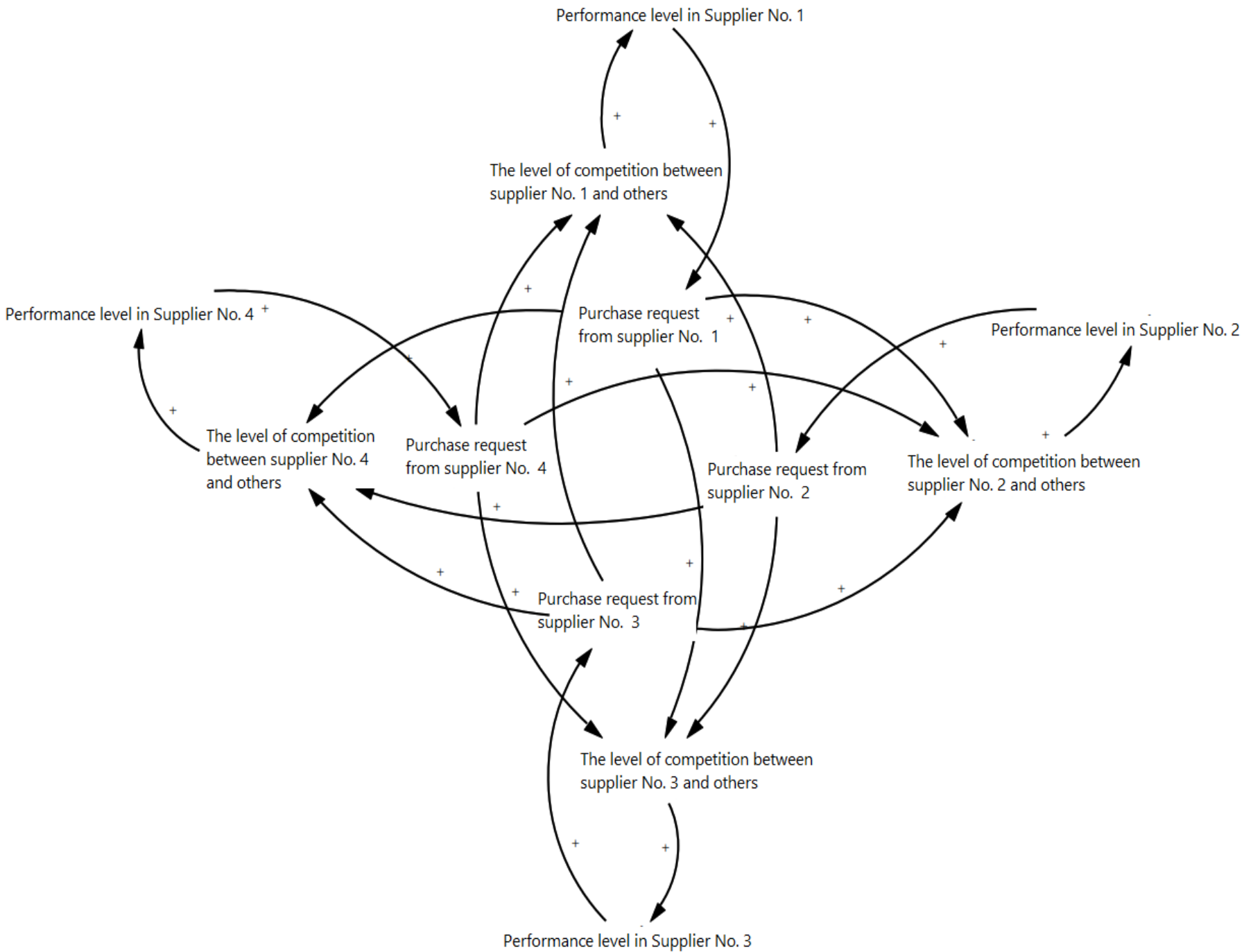

Fig. 4. The reinforcing loop in the model (with four suppliers)

Moreover, increasing the level of performance of suppliers Note that increasing the demand for each supplier will affect the competitiveness of other suppliers and their performance. Moreover, increasing the level of performance of suppliers will lead to more demand from the organization, which will automatically increase the income of the supplier and will lead to more profitability. By increasing profits, the company will increase the quality of its product and the high quality of the product will improve the performance of the supplier. Figure 5 shows this part of the model. 


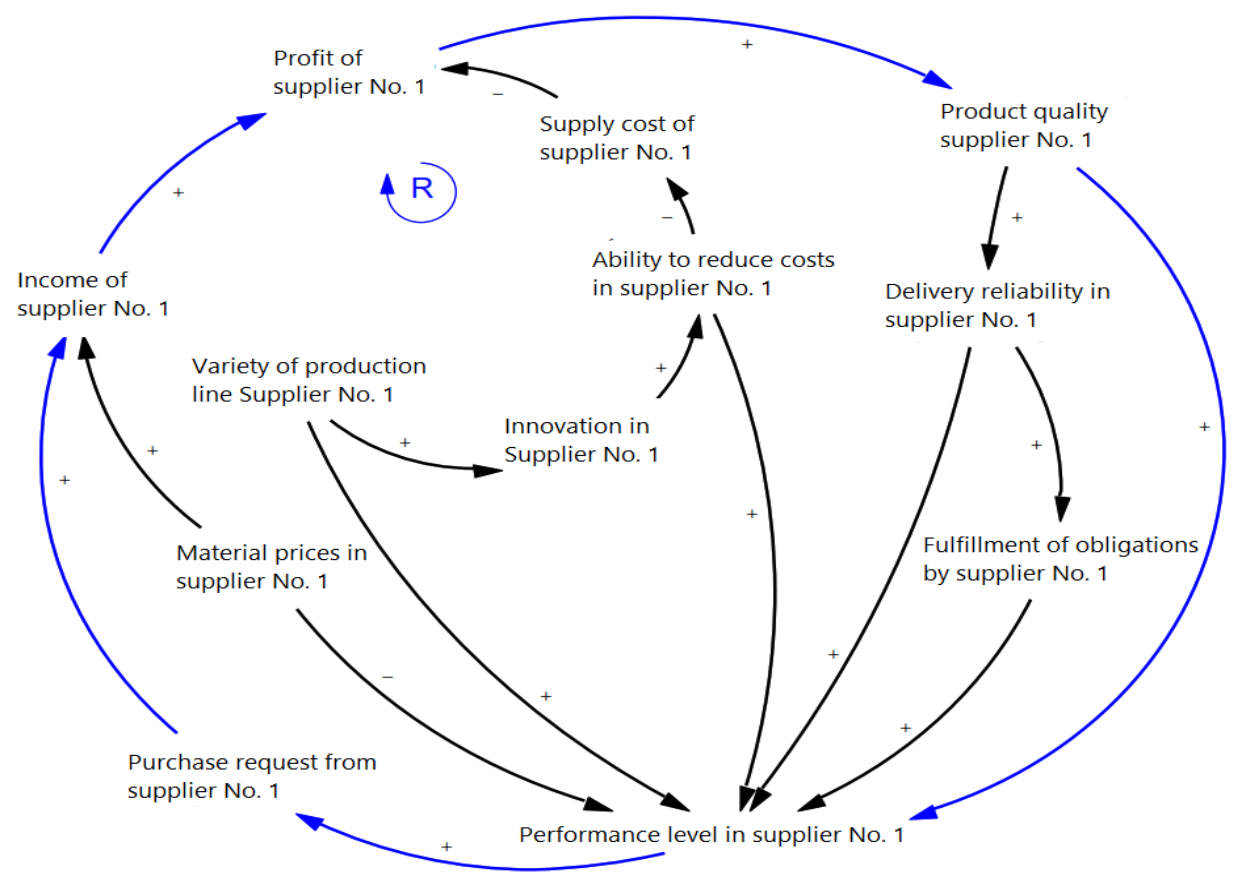

Fig. 5. The cause and effect loop that reinforces the supplier's profit

By improving product quality, the supplier will deliver more reliable products to the applicant, which will enable the supplier to perform better on its obligations to the organization and increase its performance by increasing its credibility. This part of the model is shown in Figure 6.

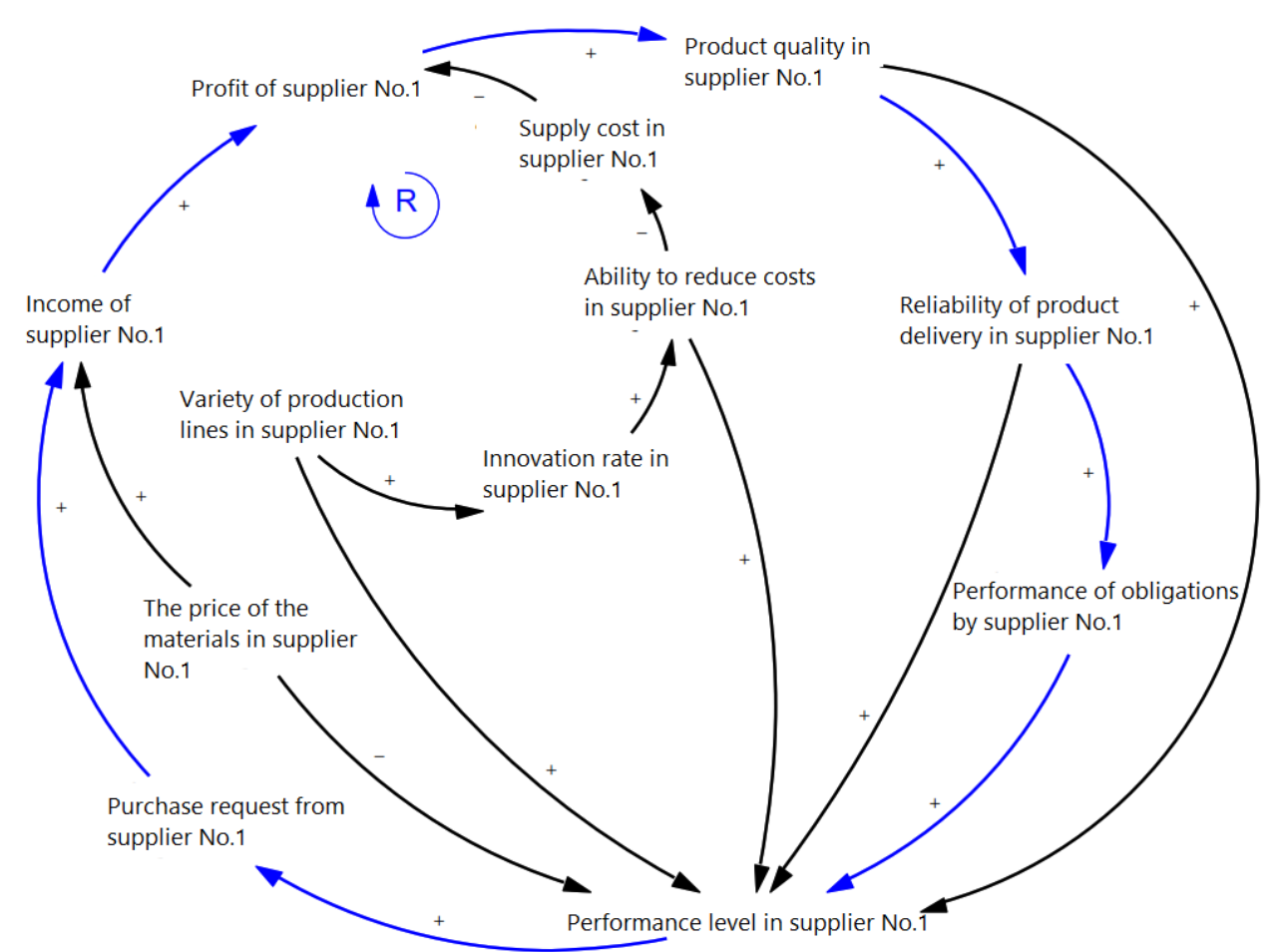

Fig. 6. Cause and effect loop related to supplier commitments 
As mentioned earlier, to simplify the cause-and-effect model, the model is shown in different sections for a supplier. In cases where the suppliers were similar in terms of the factors under consideration, the other suppliers will act as mentioned above However, it should be noted that the proposed model of this research is intended to evaluate four suppliers. Figure 7 shows an overview of the cause and effect model.

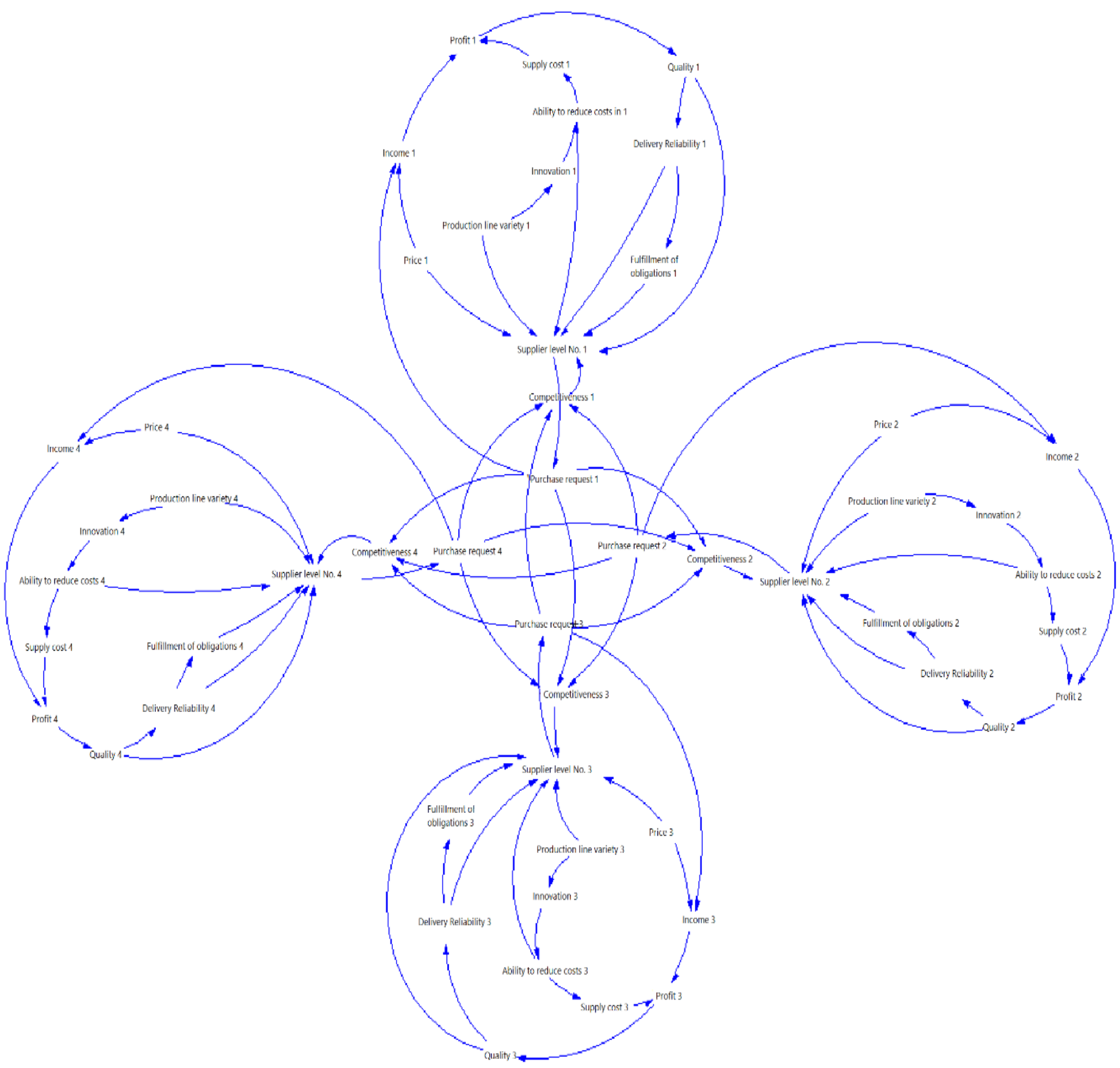

Fig. 7. Complete cause and effect diagram

\subsection{Stock-Flow Diagram}

In the previous section, the cause-and-effect model shows the interdependencies and feedback processes in the supplier evaluation system. However, due to the limitations of this diagram, one of the most important of which is the inability to display the state variable structure and flow of systems, this section shows the relevant stock-flow diagram by introducing the existing variables. The stock-flow diagram consists of various elements, which are discussed below: 
Stock variable: Stock variables (also known as stock level, inventory level, storage level, or reserve variables) are variables that determine the state of a system and create an information based on which decisions and actions are made. These variables only change over time, and their value at any given time depends on the value of this variable and other variables in previous times. These variables are displayed as rectangles. The value of each stock variable is equal to the accumulation of inflow minus outflow. In general, its mathematical concept is equal to:

$$
\operatorname{Stock}(\mathrm{t})=\int_{0}^{\mathrm{t}}(\operatorname{inflow}(\mathrm{t})-\operatorname{outflow}(\mathrm{t}))+\operatorname{Stock}\left(\mathrm{t}_{0}\right)
$$

Flow variable: Such variables describe the rate of accumulation within the system and reflect changes in stock variables over time. These variables are flows that enter or exit a stock variable. Therefore, the decision made in the form of flow variables affects stock variables over time. Input flows are represented by an arrow whose head is towards the stock variable and output flows are shown by an arrow whose head is outward to the stock variable.

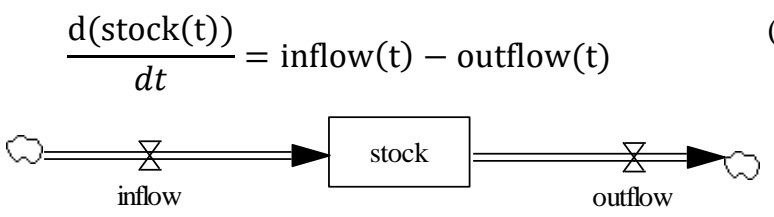

Fig. 8. Stock-Flow diagram

In this section, the relevant stock-flow charts are shown by introducing the available variables. Table 2 shows the variables and their types.

Table 2 shows that while the organization evaluates four suppliers, the model has four stock variables and four flow variables, and the other variables are auxiliary variables. Figure 9 shows the corresponding diagram.

Table 2. Stock-flow variables and their types

\begin{tabular}{|c|c|c|c|c|c|}
\hline Row & Variable & Type & Row & Variable & Type \\
\hline 1 & The performance level of supplier 1 & Stock & 12 & Request to purchase from supplier 4 & Endogenous \\
\hline 2 & The performance level of supplier 2 & Stock & 13 & Competitiveness of supplier 1 with others & Endogenous \\
\hline 3 & The performance level of supplier 3 & Stock & 14 & Competitiveness of supplier 2 with others & Endogenous \\
\hline 4 & The performance level of supplier 4 & Stock & 15 & Competitiveness of supplier 3 with others & Endogenous \\
\hline 5 & Performance increase rate of supplier 1 & Flow & 16 & Competitiveness of supplier 4 with others & Endogenous \\
\hline 6 & Performance increase rate of supplier 2 & Flow & 17 & Material price of supplier 1 & Exogenous \\
\hline 7 & Performance increase rate of supplier 3 & Flow & 18 & Material price of supplier 2 & Exogenous \\
\hline 8 & Performance increase rate of supplier 4 & Flow & 19 & Material price of supplier 3 & Exogenous \\
\hline 9 & Request to purchase from supplier 1 & Endogenous & 20 & Material price of supplier 4 & Exogenous \\
\hline 10 & Request to purchase from supplier 2 & Endogenous & 21 & The income of supplier 1 & Endogenous \\
\hline 11 & Request to purchase from supplier 3 & Endogenous & 22 & The income of supplier 2 & Endogenous \\
\hline 23 & The income of supplier 3 & Endogenous & 43 & The supplying cost for supplier 3 & Endogenous \\
\hline 24 & The income of supplier 4 & Endogenous & 44 & The supplying cost for supplier 4 & Endogenous \\
\hline 25 & The profit of supplier 1 & Endogenous & 45 & Ability to reduce costs by supplier 1 & Endogenous \\
\hline 26 & The profit of supplier 2 & Endogenous & 46 & Ability to reduce costs by supplier 2 & Endogenous \\
\hline 27 & The profit of supplier 3 & Endogenous & 47 & Ability to reduce costs by supplier 3 & Endogenous \\
\hline 28 & The profit of supplier 4 & Endogenous & 48 & Ability to reduce costs by supplier 4 & Endogenous \\
\hline 29 & The material quality of supplier 1 & Endogenous & 49 & Level of innovation in supplier 1 & Endogenous \\
\hline 30 & The material quality of supplier 2 & Endogenous & 50 & Level of innovation in supplier 2 & Endogenous \\
\hline 31 & The material quality of supplier 3 & Endogenous & 51 & Level of innovation in supplier 3 & Endogenous \\
\hline 32 & The material quality of supplier 4 & Endogenous & 52 & Level of innovation in supplier 4 & Endogenous \\
\hline
\end{tabular}


INTERNATIONAL JOURNAL Of ENGINEERING TECHNOLOGIES-IJET

Seraji, Mehrmanesh, Kasraee, Vol.7, No.2, 2021

\begin{tabular}{|c|c|c|c|c|c|}
\hline 33 & Delivery reliability of supplier 1 & Endogenous & 53 & Business experience of supplier 1 & Exogenous \\
\hline 34 & Delivery reliability of supplier 2 & Endogenous & 54 & Business experience of supplier 2 & Exogenous \\
\hline 35 & Delivery reliability of supplier 3 & Endogenous & 55 & Business experience of supplier 3 & Exogenous \\
\hline 36 & Delivery reliability of supplier 4 & Endogenous & 56 & Business experience of supplier 4 & Exogenous \\
\hline 37 & $\begin{array}{l}\text { The obligations fulfillment level by } \\
\text { supplier } 1\end{array}$ & Endogenous & 57 & The acceptance rate of risk in supplier 1 & Exogenous \\
\hline 38 & $\begin{array}{l}\text { The obligations fulfillment level by } \\
\text { supplier } 2\end{array}$ & Endogenous & 58 & The acceptance rate of risk in supplier 2 & Exogenous \\
\hline 39 & $\begin{array}{l}\text { The obligations fulfillment level by } \\
\text { supplier } 3\end{array}$ & Endogenous & 59 & The acceptance rate of risk in supplier 3 & Exogenous \\
\hline 40 & $\begin{array}{l}\text { The obligations fulfillment level by } \\
\text { supplier } 4\end{array}$ & Endogenous & 60 & The acceptance rate of risk in supplier 4 & Exogenous \\
\hline 41 & The supplying cost for supplier 1 & Endogenous & 61 & Documentation of Supplier 1 & Exogenous \\
\hline 42 & The supplying cost for supplier 2 & Endogenous & 62 & Documentation of Supplier 2 & Exogenous \\
\hline 63 & Documentation of Supplier 3 & Exogenous & 68 & Production line flexibility in supplier 4 & Exogenous \\
\hline 64 & Documentation of Supplier 4 & Exogenous & 69 & Business restrictions of supplier 1 & Exogenous \\
\hline 65 & Production line flexibility in supplier 1 & Exogenous & 70 & Business restrictions of supplier 2 & Exogenous \\
\hline 66 & Production line flexibility in supplier 2 & Exogenous & 71 & Business restrictions of supplier 3 & Exogenous \\
\hline 67 & Production line flexibility in supplier 3 & Exogenous & 72 & Business restrictions of supplier 4 & Exogenous \\
\hline
\end{tabular}

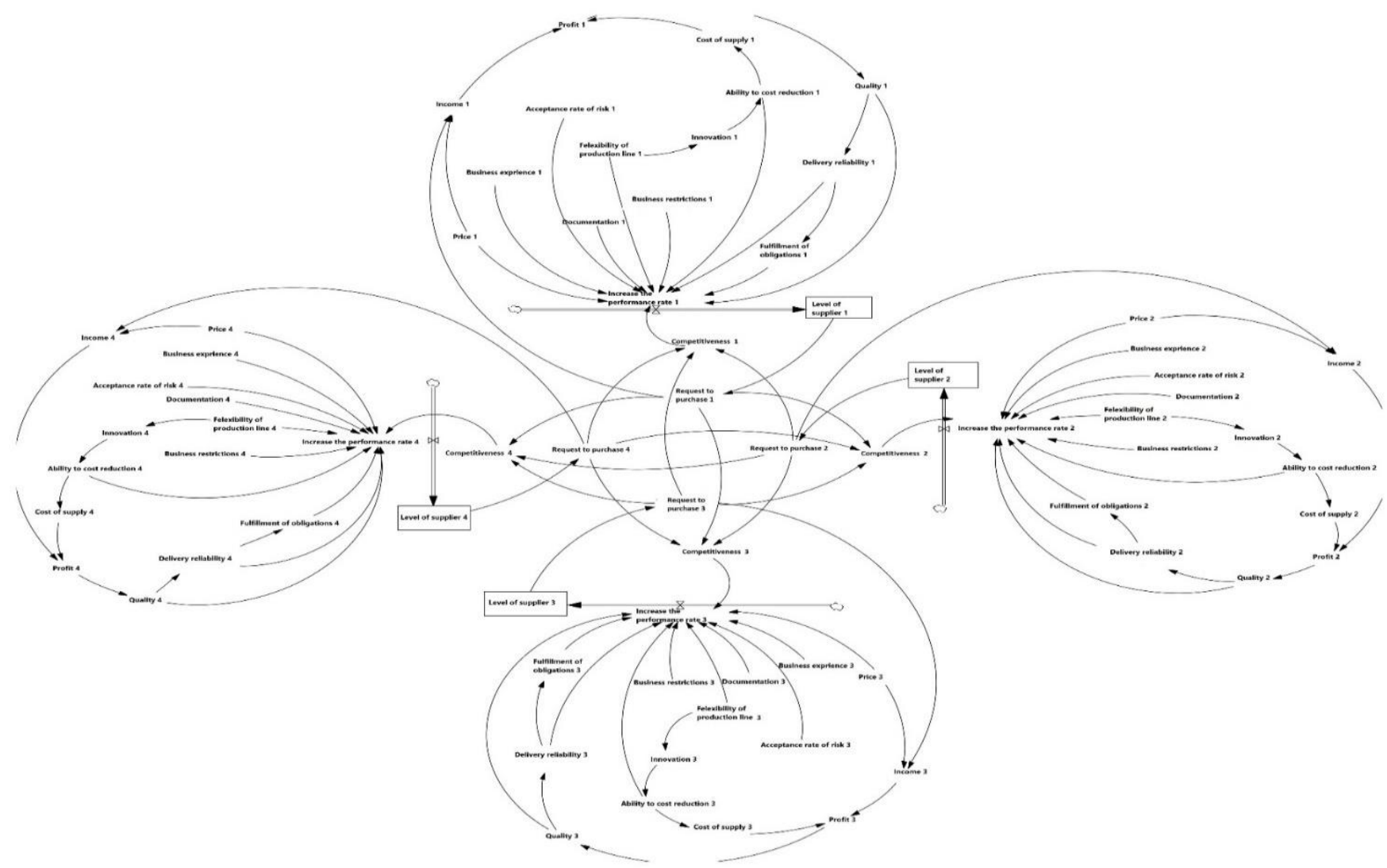

Fig. 9. Stock-Flow Diagram 


\section{Model Validation}

In this study, after simulation, the validity of the proposed model has been examined by several tests, the results of which are given below.

\subsection{Boundary Adequacy Test}

This test examines that important concepts related to the problem are considered within the model. In this study, the proposed model and its key variables have been identified and entered into the model based on literature review and expert opinions. In answer to the question of whether the behavior of the model shows a significant change after removing the assumptions of the boundary, the results of the proposed model were examined after removing parts of the model and changing the boundary of the model. Figure 10 shows the effect of deleting the "Purchase request" variable.

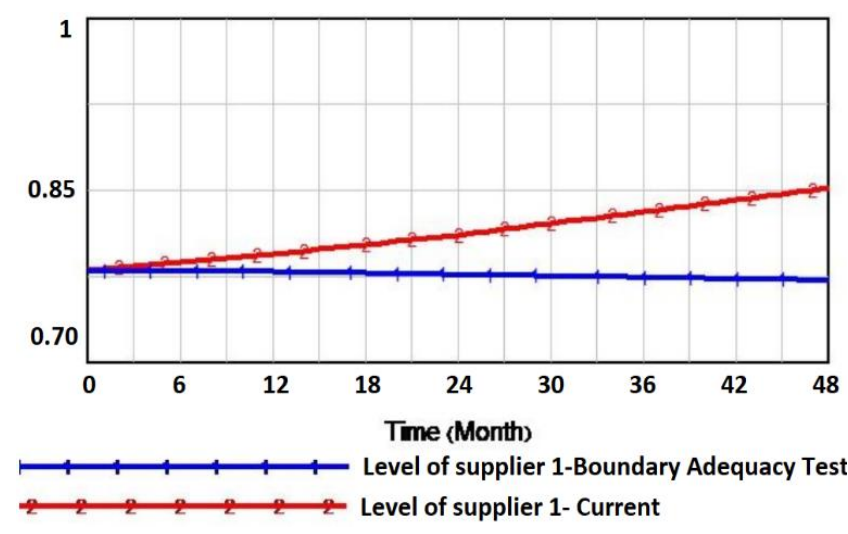

Fig. 10. Sensitivity analysis of the model to the purchase request variable in supplier 1

The red line refers to the case where there is a purchase request from supplier 1 . In the blue line, this variable is assumed to be deleted. As can be seen in the blue chart, if there is no demand from the organization, as expected, the supplier's level will not grow much because its revenue and profit will decrease, and it will remain at the same level as before. From the addition of the amount produced to the amount of the initial inventory, it remains at the same level, and due to the lack of demand, there will be no delivery to other levels of the supply chain. This test can be performed for other suppliers and other variables.

\subsection{Structure Verification Test}

The purpose of this test is to determine the compatibility of the model structure with the descriptive knowledge related to the system and to examine the rationality of the decision rules in shaping the behavior of the variables and the correct structure of the model equations. Since in this study, the model equations are written in Vensim software, the correctness of the model equation structure was confirmed by the software (Figure 11).

\section{Analysis and Conclusion}

Considering that the supplier selection is one of the important factors of profitability and survival of an organization, it is very important to choose a supplier that can sustain its status for a long time. on the other hand, how the suppliers behave and how they behave in front of other competitors, we have simulated and simulated a dynamic system model in the Vensim software to make a clear understanding of the behavior of suppliers and how each supplier behaves as it takes into account all the different aspects related to it, without affecting the other suppliers. The model structure is designed so that competition among the suppliers is considered so that if any of the suppliers face the risk they may start to change their performance and improve their performance. The systematic approach related to this study presents the evaluation results by considering the dynamic behavior of parameters and suppliers. 
After examining the criteria for selecting and evaluating suppliers and modeling their quantitative and qualitative behaviors through system dynamics, the validity of the model was tested in different ways. The aim was to show from the changes are made to each of the indicators. To this purpose, the scores of each indicator were recorded separately for each of the suppliers at the end of the two 12-month periods, and according to them and the feedback behaviors in the

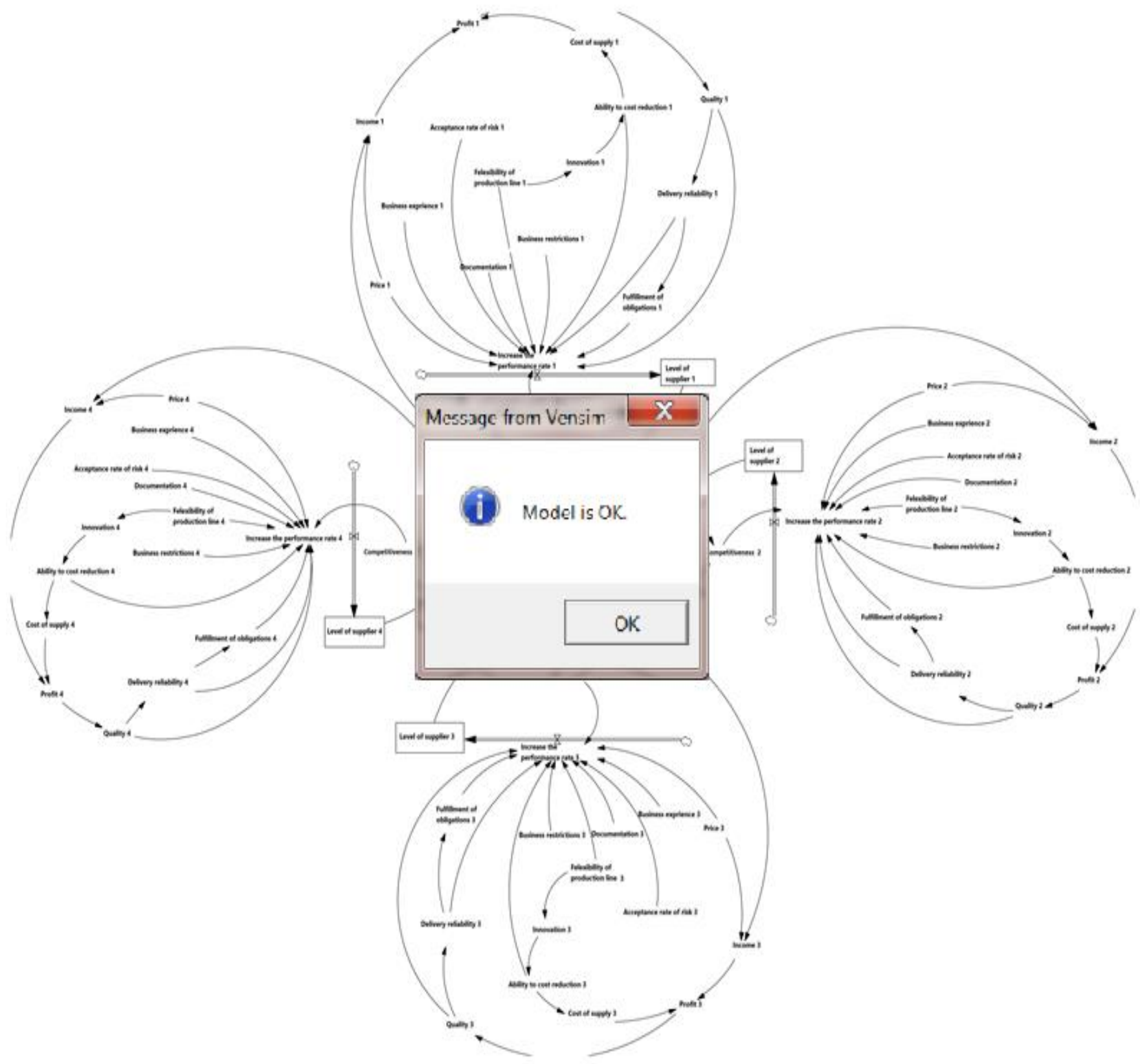

Fig. 11. Approval of model structure

output of the tests how much confidence the suppliers could have in predicting the future performance level of the suppliers. Suppliers were selected and evaluated based on the most important criteria extracted from the survey with a questionnaire and interviews with experts, which were often general criteria.

However, further efforts were made to take into account the competitive behaviors of suppliers and to use the system dynamics approach to simultaneously identify and prioritize each of them. Besides, proper decisions can be made if evaluation system, their performance was simulated for later periods.

Figure 12 shows the results of this simulation. It should be noted that the performance of each supplier has been evaluated on a scale of zero to one. 


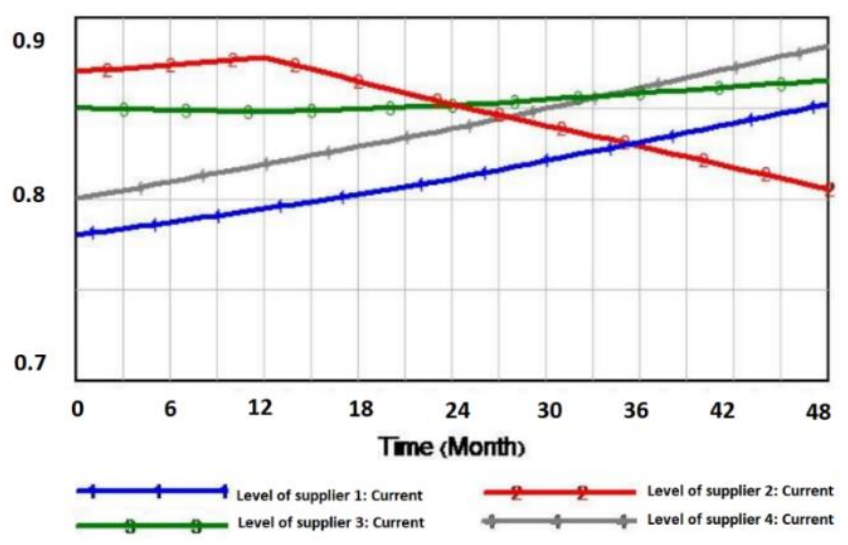

Fig. 12. Performance level of suppliers

As can be seen from Figure 12, the level of performance of supplier 2 is better than others. However, soon after that, the downtrend began, and it seems that the selection of this supplier is acceptable only in a short period. For supplier 4, although initially, its performance is not significant compared to supplier 2's performance, after a while it performs became better than other competitors in the medium term. To select a supplier in a long-term period, the supplier 3 first follows a growing performance to the extent that at the end of 48 months, its performance is better than other suppliers.

Obviously, if the organization's goals are set in such a way that it can select suppliers in combination, it is possible to propose a combination of suppliers 2,3 , and 4, respectively, 2-4-3. In this way, at the beginning of the work, priority should be given to the selection of supplier 2, and then the suppliers 4 and 3 should be used, respectively.

According to the findings and limitations of the present study, suggestions and orientations of research including: doing research for other sectors and organizations operating in those sectors to increase the capability of generalization and key results, in consideration of the political and economic factors governing the Razi institute, review further measures in future studies.

\section{References}

[1] Mazarei, S. (2017). A Review of the Role of Electronic Logistics Chain Management on Business, . International Conference on Green Supply Chain, Pishgaman Science Evaluation Company. Lahijan.

[2] Koushki-Jahromi, F., \& Safaei, M. (2020). Designing an Integrated Sustainable Supply Chain Model and its Impact on Global Competitiveness Performance by Case Study of the Turkish Pharmaceutical Industry. Talent development and excellence, 12(2s), 1121-1131.

[3] de Conto, S., Antunes Júnior, J., \& Roehe Vaccaro, G. (2016). Innovation as a competitive advantage issue: a cooperative study on an organic juice and wine producer. Gestão \& Produção, 23(2), 397-407.
[4] Safaei, M., \& Thoben, K. D. (2014). Measuring and evaluating of the network type impact on time uncertainty in the supply networks with three nodes. Measurement, $56,121-127$.

[5] González, M., Quesada, G., \& Mora Monge, C. (2004). Determining the importance of the supplier selection process in manufacturing: a case study. International Journal of Physical Distribution \& Logistics Management, 34(6), 492-504.

[6] Safaei, M. (2020). Investigating and Extracting Green Marketing Strategies for Eco-Friendly Packaging in the Food and Pharmaceutical Supply Chain (Case Study of Arian Daru Pharmaceutical Company). International Journal of Advanced Science and Technology, 29(7s), 2304-2327.

[7] Nezamoddini, N., Gholami, A., \& Aqlan, F. (2020). A risk-based optimization framework for integrated supply chains using genetic algorithm and artificial neural networks. International Journal of Production Economics, $225,107569$.

[8] Chang, J. (2017). The effects of buyer-supplier's collaboration on knowledge and product innovation. Industrial Marketing Management, 65(1), 129-143.

[9] Barati, M. (2017). The Effect of Supply Chain Relationship Management on the Competitiveness of Small and Medium-Sized Enterprises in Automobile Industry. Industrial Management Perspective, 26(1), 169188.

[10] Dombrowski, U., \& Karl, A. (2016). Systematic Improvement of Supplier Integration within the Product Development Process. Procedia CIRP, 57(1), 392-397.

[11] Karim, M., Tahera, U., \& Nasrin, S. (2020). Supply Chain Management: Materialization of Process Management to Attain Greater Accomplishment in Business Function. Fareast International University Journal, 3(1), 104-120.

[12] Rao, R., Scherholz, M., Hartmanshenn, C., Bae, S., \& Androulakis, I. (2017). On the analysis of complex biological supply chains: From process systems engineering to quantitative systems pharmacology. Computers \& Chemical Engineering, 107, 100-110.

[13] Sterman, J. (2000). Business dynamics: systems thinking and modeling for a complex world. McGraw-Hill.

[14] Nabavi, E., Daniell, K., \& Najafi, H. (2017). Boundary matters: the potential of system dynamics to support sustainability? Journal of Cleaner Production, 140(1), 312-323.

[15] Bhattacharya, S., Gupta, A., \& Hasija, S. (2014). Joint Product Improvement by Client and Customer Support Center: The Role of Gain-Share Contracts in Coordination. Information Systems Research, 25(1), 1-30. 
[16] Chen, J., \& Paulraj, A. (2004). Towards a Theory of Supply Chain Management: The Constructs and Measurements. Journal of Operations Management, 22(2), 119-150.

[17] Delbufalo, E. (2012). Outcomes of inter-organizational trust in supply chain relationships: a systematic literature review and a meta-analysis of the empirical evidence. Supply Chain Management: An International Journal, 17(4), 377-402.

[18] Dobre, O. (2013). Employee motivation and organizational performance. Review of Applied SocioEconomic Research, 5(1), 53-60.

[19] Gnyawali, D., Madhavan, R., He, J., \& Bengtsson, M. (2016). The competition-cooperation paradox in interfirm relationships: A conceptual framework. Industrial Marketing Management, 53(1), 7-18.

[20] Hajati, A. (2016). The Effect of Supply Chain Integrity on Customer Satisfaction and Financial Performance Case Study:Ahwaz Industrial Township Company. The First International Conference on New Achievements in Research, Management, Accounting and Economics. Baku.

[21] Huo , B., Qi , Y., Wang, Z., \& Zhao, X. (2015). The impact of supply chain integration on firm performance: The moderating role of competitive strategy. Supply Chain Management, 19(4), 369-384.

[22] IQVIA ${ }^{\mathrm{TM}}$. (2019). IQVIA ${ }^{\mathrm{TM}}$ MARKET PROGNOSIS. Thailand: IQVIA ${ }^{\mathrm{TM}}$.

[23] Karamehic, J., Ridic, O., Ridic, G., Jukic, T., Coric, J., Subasic, D., . . . Masic, I. (2013). Financial Aspects and the Future of the Pharmaceutical Industry in the United States of America. Mater Sociomed, 25(4), 286-290.

[24] Kwon , I.-W., Kim, S., \& Martin, D. (2016 ). Healthcare supply chain management; strategic areas for quality and financial improvement. Technological Forecasting and Social Change, 113(1), 422-428.

[25] Parmigiani, A., \& Rivera-Santos, M. (2015). Sourcing for the base of the pyramid: Constructing supply chains to address voids in subsistence markets. Journal of Operations Management, 33-34(1), 60-70.

[26] Porter, M. (2008). Competitive Strategy: Techniques for Analysing Industries andCompetitors. New York: Free Press.

[27] Prajogo, D., Chowdhury, M., Yeung,, A., \& Cheng, T. (2012). The Relationship between Supplier Management and Firm's Operational Performance: A Multidimensional Perspective. International Journal of Production Economics, 136(1), 123-130.

[28] Safaei, M., \& Nasrollahi, M. (2020). A multi-objective model to allocate multiple facilities at proposed locations in the multi-floor organization, using an improved genetic algorithm. Case Study Isfahan Governorate. International
Journal of Mathematics in Operational Research, 1(1), 120.

[29] Safaei, M., Mehrsai, A., \& Thoben, K. (2014). A computational method in analyzing of delivery time uncertainty for highly complex supply networks. Measurement, 55, 549-563.

[30] Samson, D., \& Gloet, M. (2018). Integrating performance and risk aspects of supply chain design processes. Production Planning \& Control: The Management of Operations, 29(15), 1238-1257.

[31] Stienmetz , J., \& Fesenmaier , D. (2017). Structural Implications of Destination Value System Networks. Schegg R., Stangl B. (eds) Information and Communication Technologies in Tourism, (pp. 159-171). Springer, Cham. 